\title{
PENGARUH SANKSI PERPAJAKAN, PELAYANAN FISKUS DAN PENGETAHUAN PERPAJAKAN TERHADAP KEPATUHAN WAJIB PAJAK ORANG PRIBADI (Studi Empiris Pada Wajib Pajak Orang Pribadi yang Terdaftar di KPP Pratama Jayapura)
}

\author{
Bilha M. F. Mandowally 1 \\ bilhamandowally257@gmail.com \\ Theo Allolayuk, SE., M.Si., Ak., CA ${ }^{2}$ \\ Cornelia Desiana Matani, SE., M.Mgt (Acc) $)^{3}$ \\ Jurusan Akuntansi, Fakultas Ekonomi dan Bisnis Universitas Cenderawasih
}

\begin{abstract}
This research aims to see the effect of tax sanctions, tax services, and tax knowledge on individual taxpayer compliance. The independent variables used are taxation sanctions, tax authorities, and tax knowledge while the dependent variable is taxpayer compliance. The population in this study is an individual taxpayer registered at KPP Pratama Jayapura, using a survey method, by distributing questionnaires directly to taxpayers found at the Jayapura municipal office by researchers. The analytical method used in this study is multiple linear regression with SPSS 16 test. Based on the results of the analysis show taxation sanctions partially affect the individual taxpayer compliance seen from the significance smaller than 0.05, namely (0.008), tax authorities' services affect compliance Individual taxpayers seen from the significant value is smaller than 0.05, that is $(0,000)$, and knowledge of taxation affects the individual taxpayer compliance seen from the significance smaller than 0.05, that is (0.007).
\end{abstract}

Keywords : taxation sanctions, tax authorities and knowledge of taxation, tax compliance.

\section{PENDAHULUAN}

Penerimaan pajak merupakan sumber pembiayaan dan pembangunan nasional untuk meningkatkan kesejahteraan masyarakat. Banyak Negara dimasa krisis global menjadikan pajak sebagai isntrumen ekonomi untuk memberikan kehidupan demi berlangsungnya pembangunan yang berkesinambungan.

Terbukti dengan adanya pertumbuhan kemajuan pembangunan disemua bidang, pemerintah membutuhkan biaya yang tak terbatas jumlahnya untuk meningkatkan pembangunan didaerah tersebut (Endah Wulandari, Kartika Hendra Ts, 2016). Seiring dengan pengembangan kebutuhan pembangunan itu sendiri, dana yang dibutuhkan juga semakin besar (Dharma \& Ketut Alit Suardana, 2014a). Oleh sebab itu pemerintah daerah harus berusaha keras untuk bisa meningkatkan sumber potensi pendapatan daerahnya dari pajak.

Dari data penelitian yang didapat dari kantor pelayanan pajak pratama jayapura jumlah Wajib Pajak Orang Pribadi per juni tahun 2019 sebanyak 184.596 yang terdaftar di KPP Pratama Jayapura yang terdiri dari Wajib Pajak Orang Pribadi non Karyawan sebanyak 23.266 dan Karyawan 22.194.

Dari data fakta yang terjadi di kpp pratama jayapura bahwa kepatuhan wajib pajak orang pribadi untuk melapor dan membayar pajak belum maksimal sehingga belum mencapai target yang sudah di tentukan kepala KPP Pratama Jayapura.

\footnotetext{
$\overline{{ }^{1} \text { Alumni Jurusan Akuntansi FEB Uncen }}$

${ }^{2}$ Dosen Jurusan Akuntansi FEB Uncen

3 Dosen Jurusan Akuntansi FEB Unce
} 
Karena kita tau bahwa, pajak adalah salah satu PAD terbesar dan dari pajak itulah kita dapat menujang kebutuhan yang dibutuhkan oleh daerah demi kemakmuran rakyat.

Berdasarkan uraian di atas, maka peneliti melakukan penelitian dengan tujuannya ialah menguji pengaruh sanksi perpajakan, pelayanan fiskus, dan pengetahuan perpajakan terhadap kepatuhan wajib pajak orang pribadi, adapun perbedaan dari penelitian sebelumnya adalah mengurangi dan mengubah variabel independen, yaitu mengurangi variabel kesadaran perpajakan serta menambah variabel pengetahuan perpajakan. Perbedaan selanjudnya mengenai lokasi penelitian dimana penelitian ini dilakukan di KPP Pratama Jayapura.

Tujuan daripada penelitian ini yaitu 1). untuk mengethuai apakah sanksi perpajakan berpengaruh terhadap kepatuhan wajib pajak. 2). untuk mengetahui apakah pelayanan fiskus berpengaruh terhadap kepatuhan wajib pajak orang pribadi. dan 3). untuk mengetahui apakah pengetahuan perpajakan berpengaruh terhadap kepatuhan wajib pajak orang pribadi.

\section{TINJAUAN PUSTAKA}

\subsection{Theory of Planned Behavior (TPB)}

Ditimbulkan oleh individu yang mempunyai niat untuk berperilaku.

Penelitian terkait dengan kepatuhan pajak sudah banyak dilaksanakan. Penelitian sebelumnya juga yang menggunakan teori tersebut yaitu penelitian (Fitria, 2017). Dikaitkan bersamaan dengan penelitian ini, Theory of Planned of Behavior relevan untuk menginterpresentasikan perilaku wajib pajak untuk dapat memenuhi semua kewajiban perpajakannya. Sebelum individu melakukan sesuatu, individu akan memiliki keyakinan mengenai hasil yang akan diperoleh dari perilakunya tersebut. Dengan demikian yang bersangkutan akan menentukan bahwa akan melakukannya atau tidak melakukannya. Hal tersebut berhubungan dengan kepatuhan wajib pajak. Wajib pajak yang patuh terhadap pajak, akan memiliki keyakinan terhadap pentingnya membayar pajak untuk dapat dengan mudah membantu menyelenggarakan pembangunan Negara (behavioral beliefs).

\subsection{Teori Daya Pikul}

beban pajak untuk semua harus sama beratnya, artinya pajak perlu dibayar sesuai dengan daya pikul masing-masing. Untuk mengukur daya pikul digunakan dua pendekan yaitu:

1. Unsur objektif, banyaknya penghasilan atau kekayaan yang dimiliki oleh seseorang

2. Unsur subjektif, dengan memperhatikan banyaknya kebutuhan material yang harus dipenuhi.

\subsection{Pengertian Pajak}

Pajak adalah iuran wajib yang dipungut oleh pemerintah (kewajiban pajak) untuk penggunaan rutin dan pembangunan tanpa balas jasa.

Pengertian pajak menurut para ahli dan UU: menurut Prof. Dr. PJA Adrian "pajak adalah iuran untuk Negara yang dapat dipaksakan berdasarkan peraturan, tidak dapat digunakan untuk pengeluaran umum".

\subsection{Sanksi Perpajakan}

Kementerian Keuangan Nomor KEP-95/PJ/2019. Dalam undang-undang perpajakan dikenal dengan dua sanksi yaitu sangsi administrasi dan sanksi pidana. Ancaman atas pelanggaran didalam suatu norma perpajakan ada yang diancam menggunakan sanksi administrasi saja, ada pula yang diancam menggunakan sanksi pidana, dan ada pula juga yang diancam dengan sanksi administrasi dan pidana. 


\subsection{Pelayanan Fiskus}

Pelayanan adalah teknik dalam melayani (membantu mengawasi atau menyiapkan segala keperluan yang dibutuhkan seseorang). Pelayanan fiskus dapat diartikan sebagai cara petugas pajak dalam membantu menyiapkan setiap kebutuhan yang dibutuhkan wajib pajak (Arum \& Zulaikha, 2012)

Teori pembelajaran sosial menjelaskan bahwa seseorang dapat belajar lewat observasi dan pengalaman langsung (Azwar, 2005). Apabila karakteristik mempunyai pengetahuan langsung dari pelayanan yang diberikan fiskus sehingga wajib pajak akan patuh dalam membayar pajak (Aryobimo, 2012)).

\subsection{Pengetahuan Perpajakan}

Pengetahuan adalah informasi yang diketahui atau didasari oleh seseorang melalui pola pikirnya dalam mengetahui benda atau keadaan tertentu dan tidak pernah dilihat atau dirasakan sebelumnya.

Pengetahuan perpajakan dapat juga diartikan dengan segala sesuatu yang diketahui dan dipahami sehubungan dengan hukum pajak, baik hukum pajak material maupun hukum pajak formal. Dengan wajib pajak mengetahui dan memahami seluruh ketentuan terkait dengan kewajiban perpajakan yang berlaku maka dengan sendirinya wajib pajak akan sangat mudah melaksanakan kewajiban perpajakannya (Prof. Dr. Mardiasmo, Mba., 2016) Menurut Caroline (2009: 7), Pengetahuan pajak adalah penjelasan pajak yang digunakan wajib pajak menjadi dasar untuk bertindak dalam mengambil keputusan khususnya di bidang perpajakan.

\subsection{Kepatuhan Wajib Pajak}

Definisi Kepatuhan Wajib Pajak menurut Safri Nurmantu dalam (Merckx, Bidartondo, \& Hynson, 2009) adalah: "Kepatuhan Wajib Pajak dapat dijelaskan seperti kondisi Wajib Pajak dapat memenuhi kewajiban perpajakan dan melakukan hak perpajakannya." menurut Machfud Sidik (Rahayu, 2017), mengemukakan bahwa: "Kepatuhan dalam melakukan kewajiban perpajakan dengan sukarela (voluntary of complince) merupakan tulang punggung sistem self assessment, yaitu Wajib Pajak menetapkan sendiri kewajiban perpajakan dan akhirnya dengan tepat waktu membayar dan melaporkan pajak tersebut."

\subsection{Penelitian Terdahulu dan Pengembangan Hipotesis}

\section{Pengaruh Sanksi Perpajakan Terhadap Kepatuhan Wajib Pajak}

Menurut (Mardiasmo, 2011b) sanksi perpajakan adalah jaminan bahwa keputusan peraturan perundang-undangan perpajakan (norma perpajakan) tentu dituruti/ditaati/dipatuhi. Atau dengan kata lain sanksi perpajakan menjadi alat agar wajib pajak jangan melanggar norma perpajakan. Penerapan sanksi diterapkan sebagai dampak belum terlaksananya kewajiban perpajakan oleh wajib pajak sama halnya diamanatkan oleh undang-undang perpajakan. Wajib pajak akan patuh asalkan mereka berfikir adanya sanksi berat akibat tindakan illegal dalam usahanya menyeludupkan pajak. Penerapan sanksi perpajakan baik administrasi (denda, bunga, kenaikan) dan pidana (kurungan atau penjara) mendorong kepatuhan wajib pajak, namun penerapan sanksi harus konsisten dan berlaku.

H1: Sanksi Perpajakan Berpengaruh Positif Terhadap Kepatuhan Wajib Pajak

\section{Pengaruh Pelayanan Fiskus Terhadap Kepatuhan Wajib Pajak}

Kepatuhan wajib pajak membayar pajak dipengaruhi oleh beberapa faktor salah satunya adalah kualitas pelayanan yang diberikan fiskus kepada wajib pajak Mangoting, (2013). Keunggulan pelayanan fiskus adalah segala kegiatan bantuan pelayanan yang dilaksanakan oleh fiskus pada kantor pelayanan pajak pratama jayapura dengan upaya memenuhi kebutuhan wajib pajak dalam rangka pelaksanaan ketentuan perundang-undangan. Tujuan pelayanan untuk menjaga agar wajib pajak dapat 
merasa puas dan yang diharapkan dapat menambah tingkat kepatuhan wajib pajak.

H2: Pelayanan Fiskus Berpengaruh Positif Terhadap Kepatuhan Wajib Pajak

\section{Pengaruh Pengetahuan Perpajakan Terhadap Kepatuhan Wajib Pajak}

Pengetahuan perpajakan menurut teori atribusi yaitu salah satu penyebab eksternal yang dapat mempengaruhi perilaku wajib pajak saat melaksanakan kewajiban perpajakannya. Jika wajib pajak dapat menerima pengaruh eksternal terebut, maka semakin luas pengetahuan tata cara perpajakan yang dapat dipahami oleh wajib pajak, dimana hal tersebut akan berdampak pada kepatuhan wajib pajak.

Pengetahuan pajak dapat diartikan sebagai tingkat kesadaran atau kepekaan para pembayar pajak terhadap peraturan pajak. Pengetahuan pajak mengacu pada proses, dimana para pembayar pajak menjadi sadar akan undang-undang pajak dan informasi terkait pajak lainnya (Hasseldine et al.,2009).

\section{H3: Pengetahuan Perpajakan Berpengaruh Positif Terhadap Kepatuhan Wajib Pajak.}

\section{METODE PENELITIAN}

\subsection{Jenis dan Sumber Data}

Jenis data yang dipakai dalam penelitian ini berupa data kualitatif yang di kuantitatifkan dengan skala likert. Dimana data tersebut berupa sanksi perpajakan, pelayanan fikus dan pengetahuan perpajakan terhadap kepatuhan wajib pajak orang pribadi diukur dengan menggunakan kuesioner berskala likert. Sumber data yang digunakan dalam penelitian, yaitu sebagai berikut:

Data primer ialah data yang didapat langsung dari wajib pajak orang pribadi yang di terdaftar di KPP Pratama Jayapura dengan cara memberikan kuesioner.

\subsection{Populasi dan Sampel}

Populasi dapat dipahami sebagai sekelompok individu atau obyek pengamatan yang minimal memiliki satu persamaan karakteristik. Populasi dalam penelitian ini adalah para wajib pajak orang pribadi (WP OP) yang ada di Kota Jayapura. Berdasarkan data dari KPP yang ada di Kota Jayapura, hingga Juli tahun 2019 tercata sebanyak 184.596 WP OP yang merupakan WP OP efektif. Tidk semua WP OP efektif ini menjadi obyek dalam penelitian ini karena jumlahnya sangat besar dan guna efisiensi waktu dan biaya. Oleh sebab itu dilakukanlah teknik sampling dengan metode proportional sampling untuk 126 sampel dari WP OP yang ada di Kota Jayapura.

\subsection{Metode Pengumpulan Data}

Pengumpulan data primer dilakukan dengan metode survey menggunakan media angket (kuesioner). Sejumlah pernyataan diajukan kepada responden dan kemudian responden diminta menjawab sesuai dengan pendapat mereka dan responden di harapakan dapat mengembalikan kuesioner kepada peneliti dalam waktu yang telah di tentukan. Untuk menguku pendapat responden digunakanlah skala Likert lima angka yaitu mulai dari angka 5 untuk pendapat sangat setuju (SS) dan angka 1 untuk sangat tidak setuju (STS).

\subsection{Metode Analisis Data}

Analisis data digunakan untuk menyederhanakan data supaya data lebih mudah diinterpretasikan. Analisis ini dilakukan dengan menggunakan teknik analisis regresi linear berganda untuk mengolah dan membahas data yang telah diperoleh dan untuk menguji hipotesis yang diajukan. Teknik analisis regresi linear berganda dipilih untuk digunakan pada penelitian ini karena teknik regresi linear berganda dapat menyimpulkan secara langsung mengenai pengaruh masing-masing variabel bebas yang digunakan secara parsial ataupun secara bersama-sama. 
Sehingga model regresi yang digunakan adalah:

$$
\text { Patuh }=\alpha+\beta_{1} \text { Sanksi }+\beta_{2} \text { Fiskus }+\beta_{3} \text { Kesadaran }+e
$$

Dimana:

$$
\begin{array}{ll}
\text { Patuh } & \text { : Kepatuhan Wajib Pajak } \\
\alpha & : \text { Konstanta } \\
\beta 1, \beta 2, \beta 3 & : \text { Koefisien Regresi }
\end{array}
$$

Fiskus : Sikap WP Terhadap Pelayanan Fiskus

Kesadaran : Sikap WP Terhadap Kesadaran Perpajakan

Sanksi : : Sikap WP Terhadap Sanksi Perpajakan

e : Residual

\section{HASIL PENELTIAN DAN PEMBAHASAN}

\subsection{Gambaran Umum Responden}

Hasil penelitian yang dilakukan di Kantor Pelayanan Pajak (KPP) Pratama Jayapura dengan cara menyebarkan kuesioner kepada Wajib Pajak Orang Pribadi. Penelitian ini bertujuan untuk melihat pengaruh Sangsi Perpajakan, Pelayanan Fiskus dan Pengetahuan Perpajakan terhadap Kepatuhan Wajib Pajak Orang Pribadi. Jumlah responden yang akan diteliti sebanyak 126. Dari hasil proses pengumpulan data yang dilakukan peneliti, maka didapatkan sampel sebanyak 85 sampel dari para responden. Berikut adalah rincian hasil pengumpulan data: Keterangan Jumlah Presentase Jumlah kuisoner yang didistribusikan (126) (126\% ) Jumlah kuisoner yang tidak kembali (41) (41\%) Kuisoner yang dapat diolah (85) (85\%).

\subsection{Statistika Deskriptif}

Pengujian statistik deskriptif bertujuan untuk menggambarkan karakteristik data sampel dalam penelitian serta memberikan deskripsi dari masing-masing variabel yaitu sanksi perpajakan, pelayanan fiskus, pengetahuan perpajakan dan kepatuhan wajib pajak. Hasil pengujian statistik deskriptif dapat dilihat pada Tabel 1 dibawah ini:

Tabel 1

\section{Hasil Statistik Deskriptif}

\begin{tabular}{|l|c|c|c|c|c|}
\hline \multicolumn{7}{|c|}{ Descriptive Statistics } \\
\hline x1 & $\mathrm{N}$ & Minimum & Maximum & Mean & Std. Deviation \\
\hline $\mathrm{x} 2$ & 85 & 16 & 36 & 28.82 & 4.711 \\
\hline $\mathrm{x} 3$ & 85 & 20 & 40 & 30.38 & 5.064 \\
$\mathrm{Y}$ & 85 & 20 & 39 & 29.87 & 4.827 \\
\hline Valid N & 85 & 17 & 39 & 30.33 & 4.807 \\
(listwise) & 85 & & & & \\
\hline
\end{tabular}

Sumber: Hasil Pengolahan Data Primer SPSS (2019)

Hasil statistik deskriptif yang ditunjukkan pada Tabel 1 di atas, memperlihatkan bahwa hasil pengukuran deskriptif dari 85 sampel menunjukkan dari 85 sampel variabel total Sanksi Perpajakan (total X1) memiliki nilai minimum 16 nilai maximum 36, nilai mean 28.82 dengan standar deviasi 4.711 Variabel Pelayanan Fiskus (total X2) memiliki nilai minimum 20 nilai maximum 40 nilai mean 30.38 dengan standar deviasi 5.064 Variabel pengetahuan perpajakan (total X3) memiliki nilai minimum 20 nilai maximum 39 nilai mean 29.87 dengan standar deviasi 4.827. Dan variabel 
kepatuhan wajib pajak (total Y) memiliki nilai minimum 17, nilai maximum 39 nilai mean 30.33 dengan standar deviasi 4.807.

\subsection{Pengujian Hipotesis}

Uji Koefesien Determinasi $\left(R^{2}\right)$

\section{Tabel 2}

\section{Hasil Uji Determinasi (Adjusted $\mathbf{R}^{2}$ )}

Model Summaryb

\begin{tabular}{|l|l|l|l|l|}
\hline Model & $\mathrm{R}$ & $\mathrm{R}$ Square & $\begin{array}{l}\text { Adjusted R } \\
\text { Square }\end{array}$ & $\begin{array}{l}\text { Std. Error } \\
\text { of } \\
\text { Estimate }\end{array}$ \\
\hline 1 & .857 & .735 & .725 & 2.522 \\
\hline
\end{tabular}

Sumber: Hasil pengolahan data primer SPSS (2019)

Berdasarkan tabel 4.10. terlihat pada model summary dari hasil analisis regresi berganda berdasarkan hasil output diperoleh angka Adjusted R Square sebesar nilai $\mathrm{R}^{2}$ adalah 0,725 dilihat pada kolom Adjusted R Square. Hal ini berarti bahwa kontribusi variabel sangsi perpajakan (x1), pelayanan fiskus (x2) dan pengetahuan perpajakan (x3) dalam menjelaskan varibel dependen sebesar 72,5\% sedangkan sisanya $(100 \%-72,5 \%=27,5 \%)$ dijelaskan oleh factor lain diluar model yang tidak terdeteksi dalam penelitian ini.

\section{Uji statistik $t$ (Uji parsial)}

Tabel 3

\section{Hasil Uji Parsial (Uji t)}

\begin{tabular}{|c|c|c|c|c|c|c|c|c|c|}
\hline \multirow[b]{2}{*}{ Model } & & \multicolumn{2}{|c|}{$\begin{array}{l}\text { Unstandardized } \\
\text { Coefficients }\end{array}$} & \multirow{2}{*}{\begin{tabular}{|l} 
Standardized \\
Coefficients \\
Beta \\
\end{tabular}} & \multirow[t]{2}{*}{$\mathrm{T}$} & \multirow[t]{2}{*}{ Sig. } & \multicolumn{3}{|c|}{ Correlations } \\
\hline & & $B$ & Std. Error & & & & Zero-order & artial & Part \\
\hline \multirow[t]{4}{*}{1} & (Constant) & 2.318 & 1.920 & & 1.207 & .231 & & & \\
\hline & $\mathrm{X} 1$ & .230 & .085 & .225 & 2.716 & .008 & .710 & .289 & .155 \\
\hline & X2 & .470 & .080 & .496 & 5.868 & .000 & .807 & .546 & .336 \\
\hline & X3 & .238 & .086 & .239 & 2.767 & .007 & .731 & .294 & .158 \\
\hline
\end{tabular}

a. Dependent Variable: $Y$

Sumber: hasil pengolahan data primer SPSS (2019)

Berdasarkan pada hasil pengujian t pada tabel di atas, maka dapat disimpulkan sebagai berikut:

H1: $\quad$ Sanksi Perpajakan Berpengaruh Terhadap Kepatuhan Wajib Pajak Orang Pribadi. Hasil yang ditunjukan pada tabel 4.11 memiliki nilai t hitung $<\mathrm{t}$ tabel sebesar 2,716 < 1,990 dan signifikanya lebih besar dari 0,05 yaitu 0,008 > dari 0,05 maka dapat dikatakan mempunyai pengaruh signifikan antara variabel Sanksi perpajakan terhadap wajib pajak orang pribadi sehingga H1 diterima.

H2: Pelayanan Fiskus Berpengaruh Terhadap Wajib Pajak Orang Pribadi.

Hasil yang ditunjukan pada tabel 4.11 memiliki nilai t hitung > t tabel sebesar 5,868 > 1,990 dan signifikanya lebih kecil dari 0,05 yaitu 0,000 < dari 0,05 maka dapat dikatakan mempunyai pengaruh signifikan antara variabel Pelayanan Fiskus terhadap kepatuhan wajib pajak orang pribadi sehingga $\mathbf{H 2}$ diterima. 
H3: $\quad$ Pengetahuan Perpajakan Berpengaruh Terhadap Kepatuhan Wajib Pajak Orang Pribadi. Hasil yang ditunjukan pada tabel 4.11 memiliki nilai $t$ hitung > t tabel sebesar 2,767 >1,990 dan signifikanya lebih kecil dari 0,05 yaitu 0,007 < dari 0,05 maka dapat dikatakan mempunyai pengaruh signifikan antara variabel pengetahuan perpajakan terhadap kepatuhan wajib pajak orang pribadi sehingga $\mathbf{H 3}$ diterima.

Berdasarkan hasil Uji t pada tabel 4.11 dengan melihat nilai unstandardized coefficient, proses penyederhanaan persamaan regresi yang diperoleh maka dapat dijelaskan sebagai berikut:

$$
\mathrm{Y}=2,318+0,230 \times 1+0,470 \times 2+0,238 \times 3+e
$$

\subsection{Pembahasan}

\section{Pengaruh Sanksi Perpajakan Terhadap Kepatuhan Wajib Pajak Orang Pribadi}

Hasil pengujian yang diperoleh dalam penelitian ini menyatakan bahwan Variabel Sanksi perpajakan berpengaruh positif terhadap kepatuhan wajib pajak yang ada dikantor pelayanan pajak pratama jayapura. Hasil pengujian hipotesis variable sanksi perpajakan berpengaruh signifikan dan mempunyai hubungan positif terhadap kepatuhan wajib pajak orang pribadi. Berdasarkan hasil tersebut bahwa wajib pajak tidak ingin dikenakan sanksi pajak apabila mereka tidak melaksanakan kewajiban perpajakannya.

Hasil penelitian ini searah dengan penelitian yang telah dilakukan oleh (Mutia, 2014a)), dan (Indriyani \& Sukartha, 2014) yang menunjukkan bahwa sanksi pajak berpengaruh positif terhadap kepatuhan wajib pajak.

\section{Pengaruh Pelayanan Fiskus Terhadap Kepatuhan Wajib Pajak Orang Pribadi}

Hasil pengujian yang diperoleh dalam penelitian ini menyatakan Variablel Pelayanan fiskus tersebut disimpulkan bahwa secara parsial pelayanan fiskus berpengaruh secara signifikan terhadap tingkat kepatuhan wajib pajak orang pribadi di Kantor Pelayanan Pajak Pratama Jayapura karena nilai signifikasinya 0,000 yang lebih kecil dari 0.05 dan $\mathrm{t}$ hitung $>\mathrm{t}$ tabel. Sehingga dapat diartikan semakin baik pelayanan fiskus yang terkendali dan mudah dipahami maka wajib pajak akan semakin patuh dalam membayar pajaknya.

Hasil penelitian ini searah dengan hasil penelitian yang dilakukan oleh (Pranata \& Setiawan, 2015), (Rohmawati \& Rasmini, 2012), (Putri \& Setiawan, 2017) yang hasilnya menyatakan bahwa pelayanan fiskus berpengaruh terhadap kepatuhan wajib pajak orang pribadi di Kantor Pelayanan Pajak Jayapura.

\section{Pengaruh Pengetahuan Perpajakan Terhadap Kepatuhan Wajib Pajak}

Hipotesis ketiga mengenai pengetahuan perpajakan berpengaruh secara signifikan terhadap kepatuhan wajib pajak di Kantor Pelayanan Pajak Pratama Jayapura. Hal ini dapat dilihat dari nilai signifikasi 0,007 yang berarti nilai ini lebih kecil dari 0.05. Hal ini berarti semakin tinggi Pengetahuan Perpajakan maka semakin tinggi Kepatuhan Wajib Pajak. Hal ini berarti Hipotesis ketiga (x3) Pengetahuan Perpajakan berpengaruh positif dan signifikan terhadap Kepatuhan Wajib Pajak Orang Pribadi di KPP Pratama Jayapura tahun 2019 diterima. Berdasarkan uji hipotesis dapat disimpulkan bahwa variabel Pengetahuan Perpajakan berpengaruh positif terhadap Kepatuhan Wajib Pajak. Sehingga semakin tinggi Pengetahuan Perpajakan akan semakin patuh Wajib Pajak dalam memenihi kewajibannya membayar pajak. Pengetahuan itu sendiri antara lain Pengetahuan mengenai ketentuan umum dan tata cara perpajakan. 
Sependapat dengan penelitian yang dilakukan oleh (Fatmawati, 2015) mengatakan bahwa Pengetahuan Perpajakan, memiliki pengaruh positif terhadap kepatuhan wajib pajak.

\section{PENUTUP}

\subsection{Kesimpulan}

Berdasarkan analisis yang telah dilakukan maka, kesimpulan dari peneltian ini adalah:

1. Pengujian hipotesis pertama yang dilakukan membuktikan bahwa sanksi perpajakan mempunyai pengaruh yang positif dan signifikan terhadap kepatuhan wajib pajak orang pribadi.

2. Pengujian hipotesis kedua yang dilakukan bahwa pelayanan fiskus mempunyai pengaruh yang positif dan signifikan terhadap kepatuhan wajib pajak orang pribadi.

3. Pengujian hipotesis ketiga yang dilakukan bahwa pengetahuan perpajakan mempunyai pengaruh yang positif dan signifikan terhadap kepatuhan wajib pajak orang pribadi.

\subsection{Saran}

Saran yang dapat dibuat dari penelitian ini yaitu:

1. Diperlukan adanya kesadaran dari dalam diri wajib pajak untuk meningkatkan kepatuhan wajib pajak, serta petugas pajak perlu memperhatikan kualitas pelayanan yang diberikannya kepada wajib pajak, sehingga dapat meningkatkan peneriman pajak.

2. Petugas pajak harus lebih aktif pada saat memberikan informasi dan pemungutan pajak kepada wajib pajak sehingga wajib pajak tau kapan membayar dan terhindar dari sanksi.

3. Disarankan untuk penelitian lebih lanjut menggunakan variabel lain supaya dapat mengukur kepatuhan wajib pajak dan dalam pemilihan sampel yang akan dijadikan responden disarankan untuk memilih wajib pajak yang betul-betul sudah terdata sebagai wajib pajak orang pribadi. 


\section{DAFTAR PUSTAKA}

Arum, H. P., \& Zulaikha. (2012). Pengaruh Kesadaran Wajib Pajak, Pelayanan Fiskus, Dan Sanksi Pajak Terhadap Kepatuhan Wajib Pajak Orang Pribadi Yang Melakukan Kegiatan Usaha Dan Pekerjaan Bebas. Diponegoro Journal Of Accounting, 1(1), 1-8.

Aryobimo, P. T. R. I. (2012). Pengaruh Persepsi Wajib Pajak tentang Kualitas Pelayanan Fiskus terhadap Kepatuhan Wajib Pajak dengan Kondisi Keuangan Wajib Pajak dan Preferensi Risiko sebagai Variabel Moderating. Skripsi. Universitas Diponegoro.

Azwar. (2005). Teori Perilaku. Teori Perilaku, 5-28.

Cindy Jotopurnomo Dan Yenni Mangoting. (2013). Pengaruh Kesadaran Wajib Pajak, Kualitas Pelayanan Fiskus, Sanksi Perpajakan, Lingkungan Wajib Pajak Berada Terhadap Kepatuhan Wajib Pajak Orang Pribadi Di Surabaya. Tax \& Accounting Review. https://doi.org/10.1016/j.apsusc.2017.11.151

Dharma, G. P. E., \& Ketut Alit Suardana. (2014a). Pengaruh Kesadaran Wajib Pajak, Sosialisasi Perpajakan, Kualitas Pelayanan Pada Kepatuhan Wajib Pajak. E-Jurnal Akuntansi Universitas Udayana, 1, 340-353. https://doi.org/10.1007/s10802-015-0113-9

Dharma, G. P. E., \& Ketut Alit Suardana. (2014b). Pengaruh Kesadaran Wajib Pajak, Sosialisasi Perpajakan, Kualitas Pelayanan Pada Kepatuhan Wajib Pajak. E-Jurnal Akuntansi Universitas Udayana. https://doi.org/10.1007/s10802-015-0113-9

Endah Wulandari, Kartika Hendra Ts, Y. C. (2016). Faktor-Faktor Yang Mempengaruhi Kepatuhan Wajib Pajak Orang Pribadi. In Seminar Nasional IENACO.

Fatmawati, D. (2015). Pengaruh Pengetahuan Tentang Pajak, Sanksi Pajak, Dan Pemeriksaan Pajak Terhadap Kepatuhan Wajib Pajak Di Kantor Wilayah Direktorat Jenderal Pajak Daerah Istimewa Yogyakarta. Studi, Program Dan, Bahasa Indonesia, Sastra Bahasa, Fakultas Seni, D A $N$ Yogyakarta, Universitas Negeri.

Fikriningrum, W. K. (2012). Analisis Faktor-Faktor Yang Mempengaruhi Kepatuhan Wajib Pajak Orang Pribadi Dalam Membayar Pajak Penghasilan. Jurnal Akuntansi.

Fitria, D. (2017). Pengaruh Kesadaran Wajib Pajak, Pengetahuan Dan Pemahaman Perpajakan Terhadap Kepatuhan Wajib Pajak. Applied Business and Economics, 4(1), 30-44.

Ghozali, I. (2006). Analisis Multivariate Lanjutan dengan Program SPSS.

Harmawati, N. K. A., \& Yadnyana, I. K. (2016). Pengaruh Pemahaman Perpajakan , Kualitas Pelayanan,Ketegasan Sanksi Pajak Dan Pemeriksaan Pajak Pada Kepatuhan Wajib Pajak PBB-P2 Dengan Tingkat Pendidikan Sebagai Pemoderasi. E-Jurnal Ekonomi Dan Bisnis Universitas Udayana, 5(6), 1513-1542.

Indriyani, A., \& Sukartha. (2014). Tanggungjawab Moral, Kesadaran Wajib Pajak, Sanksi. E-Jurnal Akuntansi Universitas Udayana 7.2 (2014).

Mardiasmo. (2011a). Perpajakan. In Perpajakan (p. 34).

Mardiasmo, 2011:7 e siti Kurnia (2010:139). (2011b). Pengaruh Pajak penghasilan terhadap kepatuhan wajib pajak. Pengaruh Pajak Penghasilan Terhadap Kepatuhan Wajib Pajak.

Muliari, N. K., \& Ery Setiawan, P. (2011). Pengaruh Persepsi Tentang Sanksi Perpajakan Dan Kesadaran Wajib Pajak Pada Kepatuhan Pelaporan Wajib Pajak Orang Pribadi di Kantor Pelayanan Pajak Pratama Denpasar Timur. Jurnal Ilmiah Akuntansi Dan Bisnis.

Mutia, S. P. T. (2014a). Pengaruh Sanksi Pajak, Kesadaran Wajib Pajak, Pelayanan Fiskus, dan Tingkat Pemahaman Tethadap Kepatuhan Wajib Pajak Orang Pribadi. Jurnal Universitas Negeri Malang.

Mutia, S. P. T. (2014b). Pengaruh Sanksi Perpajakan, Kesadaran Perpajakan, Pelayanan Fiskus, dan Tingkat Pemahaman terhadap Kepatuhan Wajib Pajak Orang Pribadi. e-Perpajakan.

Pranata, P. A., \& Setiawan, P. E. (2015). Pengaruh Sanksi Perpajakan, Kualitas Pelayanan dan Kewajiban Moral Pada Kepatuhan Wajib Pajak. E-Jurnal Akuntansi Universitas Udayana.

Arum, H. P., \& Zulaikha. (2012). Pengaruh Kesadaran Wajib Pajak, Pelayanan Fiskus, Dan Sanksi Pajak Terhadap Kepatuhan Wajib Pajak Orang Pribadi Yang Melakukan Kegiatan Usaha Dan Pekerjaan Bebas. Diponegoro Journal Of Accounting, 1(1), 1-8.

Aryobimo, P. T. R. I. (2012). Pengaruh Persepsi Wajib Pajak tentang Kualitas Pelayanan Fiskus terhadap Kepatuhan Wajib Pajak dengan Kondisi Keuangan Wajib Pajak dan Preferensi Risiko sebagai Variabel Moderating. Skripsi. Universitas Diponegoro. 
Azwar. (2005). Teori Perilaku. Teori Perilaku, 5-28.

Cindy Jotopurnomo Dan Yenni Mangoting. (2013). Pengaruh Kesadaran Wajib Pajak, Kualitas Pelayanan Fiskus, Sanksi Perpajakan, Lingkungan Wajib Pajak Berada Terhadap Kepatuhan Wajib Pajak Orang Pribadi Di Surabaya. Tax \& Accounting Review. https://doi.org/10.1016/j.apsusc.2017.11.151

Dharma, G. P. E., \& Ketut Alit Suardana. (2014a). Pengaruh Kesadaran Wajib Pajak, Sosialisasi Perpajakan, Kualitas Pelayanan Pada Kepatuhan Wajib Pajak. E-Jurnal Akuntansi Universitas Udayana, 1, 340-353. https://doi.org/10.1007/s10802-015-0113-9

Dharma, G. P. E., \& Ketut Alit Suardana. (2014b). Pengaruh Kesadaran Wajib Pajak, Sosialisasi Perpajakan, Kualitas Pelayanan Pada Kepatuhan Wajib Pajak. E-Jurnal Akuntansi Universitas Udayana. https://doi.org/10.1007/s10802-015-0113-9

Endah Wulandari, Kartika Hendra Ts, Y. C. (2016). Faktor-Faktor Yang Mempengaruhi Kepatuhan Wajib Pajak Orang Pribadi. In Seminar Nasional IENACO.

Fatmawati, D. (2015). Pengaruh Pengetahuan Tentang Pajak, Sanksi Pajak, Dan Pemeriksaan Pajak Terhadap Kepatuhan Wajib Pajak Di Kantor Wilayah Direktorat Jenderal Pajak Daerah Istimewa Yogyakarta. Studi, Program Dan, Bahasa Indonesia, Sastra Bahasa, Fakultas Seni, D A N Yogyakarta, Universitas Negeri.

Fikriningrum, W. K. (2012). Analisis Faktor-Faktor Yang Mempengaruhi Kepatuhan Wajib Pajak Orang Pribadi Dalam Membayar Pajak Penghasilan. Jurnal Akuntansi.

Fitria, D. (2017). Pengaruh Kesadaran Wajib Pajak, Pengetahuan Dan Pemahaman Perpajakan Terhadap Kepatuhan Wajib Pajak. Applied Business and Economics, 4(1), 30-44.

Ghozali, I. (2006). Analisis Multivariate Lanjutan dengan Program SPSS.

Harmawati, N. K. A., \& Yadnyana, I. K. (2016). Pengaruh Pemahaman Perpajakan , Kualitas Pelayanan,Ketegasan Sanksi Pajak Dan Pemeriksaan Pajak Pada Kepatuhan Wajib Pajak PBB-P2 Dengan Tingkat Pendidikan Sebagai Pemoderasi. E-Jurnal Ekonomi Dan Bisnis Universitas Udayana, 5(6), 1513-1542.

Indriyani, A., \& Sukartha. (2014). Tanggungjawab Moral , Kesadaran Wajib Pajak , Sanksi. E-Jurnal Akuntansi Universitas Udayana 7.2 (2014).

Mardiasmo. (2011a). Perpajakan. In Perpajakan (p. 34).

Mardiasmo, 2011:7 e siti Kurnia (2010:139). (2011b). Pengaruh Pajak penghasilan terhadap kepatuhan wajib pajak. Pengaruh Pajak Penghasilan Terhadap Kepatuhan Wajib Pajak.

Muliari, N. K., \& Ery Setiawan, P. (2011). Pengaruh Persepsi Tentang Sanksi Perpajakan Dan Kesadaran Wajib Pajak Pada Kepatuhan Pelaporan Wajib Pajak Orang Pribadi di Kantor Pelayanan Pajak Pratama Denpasar Timur. Jurnal Ilmiah Akuntansi Dan Bisnis.

Mutia, S. P. T. (2014a). Pengaruh Sanksi Pajak, Kesadaran Wajib Pajak, Pelayanan Fiskus, dan Tingkat Pemahaman Tethadap Kepatuhan Wajib Pajak Orang Pribadi. Jurnal Universitas Negeri Malang.

Mutia, S. P. T. (2014b). Pengaruh Sanksi Perpajakan, Kesadaran Perpajakan, Pelayanan Fiskus, dan Tingkat Pemahaman terhadap Kepatuhan Wajib Pajak Orang Pribadi. e-Perpajakan.

Pranata, P. A., \& Setiawan, P. E. (2015). Pengaruh Sanksi Perpajakan, Kualitas Pelayanan dan Kewajiban Moral Pada Kepatuhan Wajib Pajak. E-Jurnal Akuntansi Universitas Udayana.

Prof. Dr. Mardiasmo, Mba., A. (2016). Perpajakan Edisi Terbaru 2016. Penerbit ANDI.

PUSTAKA, D., Abdul Rahman (2010). Panduan Pelaksanaan administrasi Perpajakan untuk Karyawan, Pelaku Bisnis, dan P. B. N., Empat., C. (2009). P. P. J. : S., Devano dan Rahayu (2010). Perpajakan: Konsep, T. dan I. J. K. P. M. G., Http://www.pajak.go.id/, D. J. P. (2014). P. P. N. 46 T. 2013. D. tanggal 1 J. 2015 dari, Komputindo, G. G. (2017). S. V. 24. S. P. dengan S. J. : E. M., ... Wahyudi, D. (2016). Pengaruh Religiusitas terhadap Perilaku Kepatuhan Wajib Pajak Orang Pribadi di Provinsi DKI Jakarta. Jurnal Lingkar Widyaiswara. https://doi.org/10.1016/S0040-4020(00)00446-4

Putri, J. K., \& Setiawan, E. P. (2017). Pengaruh Kesadaran, Pengetahuan Dan Pemahaman Perpajakan, Kualitas Pelayanan Dan Sanksi Perpajakan Terhadap Kepatuhan Wajib Pajak. E-Jurnal Akuntansi Universitas Udayana.

Rahayu, S. K. (2017). Perpajakan (Konsep dan Aspek Formal. Rekayasa Sains.

Rahma, Y. (2013). Pengaruh Tingkat Kepatuhan Wajib Pajak Badan Terhadap Peningkatan Penerimaan Pajak Yang Dimoderasi Oleh Pemeriksaan Pajak Pada KPP Pratama Padang. Jurnal Akuntansi, 1(1), 1-12. https://doi.org/10.1128/AAC.00939-09 
Rohmawati, A. N., \& Rasmini, N. K. (2012). Pengaruh Kesadaran, Penyuluhan, Pelayanan, dan Sanksi Perpajakan Pada Kepatuhan Wajib Pajak Orang Pribadi. E-Jurnal Akuntansi Universitas Udayana. https://doi.org/10.1109/TNANO.2008.926374

Widyastuti, E. (2015). Pengaruh Tingkat Pemahaman Wajib Pajak, Kualitas Pelayanan Fiskus, Sanksi Perpajakan, Dan Lingkungan Wajib Pajak Terhadapt Tingkat Kepatuhan Wajib Pajak Orang Pribadi. Universitas Muhammadiyah Surakarta.

Witono, B. (2008). Peranan pengetahuan pajak pada kepatuhan wajib pajak. Jurnal Akuntansi Dan Keuangan.

Yuniastuti, T. (2016). Pengaruh Kesadaran Wajib Pajak, Pelayanan Fiskus, Sanksi Wajib Pajak, Pemahaman Wajib Pajak, Dan Sikap Rasional Terhadap Kepatuhan Wajib. Skripsi. 